\title{
INCIDÊNCIA DE DANOS PÓS-COLHEITA EM GOIABAS NO MERCADO ATACADISTA DE SÃo PAULO E SUA RELAÇÃo COM A PRÁTICA DE ENSACAMENTO DOS FRUTOS ${ }^{1}$
}

\author{
MARISE CAGNIN MARTINS², LILIAN AMORIM, SILVIA AFONSECA LOURENÇO ${ }^{4}$, \\ ANITA SOUZA DIAS GUTIERREZ ${ }^{5}$ \& HÉLIO SATOSHI WATANABE ${ }^{6}$
}

RESUMO-A incidência de danos pós-colheita em goiabas foi quantificada no período de abril de 2005 a agosto de 2006 em quatro permissionários do Entreposto Terminal de São Paulo da Companhia de Entrepostos e Armazéns Gerais de São Paulo (CEAGESP). As amostragens foram feitas de forma estratificada, utilizando calibre, procedência, cor da polpa e ensacamento do fruto como critérios de estratificação. Injúrias mecânicas e doenças pós-colheita foram quantificadas por meio de análise visual de todos os frutos de 323 caixas de goiaba. Foram avaliados 5.081 frutos, dos quais $51,1 \%$ foram provenientes de pomares onde a prática do ensacamento dos frutos era utilizada. Injúrias mecânicas pós-colheita foram observadas em $63 \%$ dos frutos, mas apenas 5,5\% dos frutos mostraram sintomas de doenças. A incidência de doenças pós-colheita foi correlacionada à incidência de injúrias mecânicas apenas nos frutos ensacados $(\mathrm{R}=0,20, \mathrm{p}<0,05)$. Essas variáveis não foram correlacionadas nos frutos não- ensacados $(\mathrm{R}=0,09)$. Pinta-preta $($ Guignardia psidii) foi observada em 3,5 \% dos frutos e antracnose (Colletotrichum spp.), em 1,1 \% deles. Podridões pós-colheita ocasionadas pelos fungos dos gêneros Fusicoccum, Rhizopus e Pestalotia ocorreram em menos de 1\% dos frutos. A incidência de doenças provocadas por patógenos quiescentes foi significativamente maior em frutos ensacados ( $7,7 \%$ dos frutos) que em frutos nãoensacados $(2,1 \%$ dos frutos). $\mathrm{O}$ oposto foi observado para patógenos que penetram o fruto exclusivamente por ferimentos, cujas médias foram de $0,3 \%$ e $0,8 \%$ de incidência de frutos sintomáticos, respectivamente para frutos ensacados e não-ensacados. Não houve diferença estatística significativa na incidência de doenças quiescentes nos frutos ensacados das variedades de polpa branca $(7,8 \%)$ e nas variedades de polpa vermelha $(7,3 \%)$.

Termos para indexação: Psidium guajava, doenças pós-colheita, Guignardia psidii, Colletotrichum spp.

\section{INCIDENCE OF POST HARVEST DAMAGES IN GUAVAS AT THE WHOLESALE MARKET OF SÃO PAULO AND ITS RELATIONSHIP TO PRE HARVEST BAGGING}

\begin{abstract}
The incidence of post harvest damages in guavas was quantified from April 2005 to August 2006 in four wholesalers from the terminal wholesale market of São Paulo (CEAGESP). The sampling was stratified by fruit size, fruit origin, flesh color and bagging the fruit. All fruit from 323 guava boxes were visually assessed. Post harvest mechanical injuries and diseases were quantified. Five thousand and eighty one fruit were assessed, 51.1\% of which came from orchards where fruit received paper bags some time before harvesting. Post harvest mechanical injuries were observed in $63 \%$ of fruit but only 5.5\% of fruit showed symptoms of post harvest diseases. These diseases incidence was correlated to the incidence of post harvest mechanical injuries only in bagged fruit $(\mathrm{R}=0.20, \mathrm{p}<0.05)$. These variables were not correlated in fruit not bagged $(\mathrm{R}=0.09)$. Black spot (Guignardia psidii) was observed in 3.5 $\%$ of fruit and anthracnose (Colletotrichum spp.), in $1.1 \%$ of them. Post harvest rots caused by fungi from genera Fusicoccum, Rhizopus, and Pestalotia occurred in less than $1 \%$ of fruit. The incidence of post harvest diseases caused by quiescent pathogens was significantly greater in bagged fruit ( $7.7 \%$ of fruit) than in non-bagged fruit ( $2.1 \%$ of fruit). The opposite was observed for wound-pathogens, with averages of $0.3 \%$ and $0.8 \%$ of symptomatic guavas for bagged and non-bagged fruit, respectively. There was no significant difference in the incidence of quiescent diseases in bagged fruit from varieties with white flesh ( $7.8 \%)$ or red flesh $(7.3 \%)$.
\end{abstract}

Index terms: Psidium guajava, post harvest diseases, Guignardia psidii, Colletotrichum spp.

\footnotetext{
(Trabalho 164-06). Recebido em 20-10-2006. Aceito para publicação 16-03-2007. Parcialmente financiado pela FAPESP (03/10025-9).

Pesquisadora Científica, Instituto Biológico, Caixa Postal 70, 13001-970, Campinas-SP, marise@biologico.sp.gov.br.

${ }^{3}$ Bolsista CNPq, Professor Titular, Departamento de Entomologia, Fitopatologia e Zoologia Agrícola da Escola Superior de Agricultura Luiz de Queiroz, Universidade de São Paulo, Caixa Postal 9, 13418-900, Piracicaba-SP, liamorim@esalq.usp.br.

${ }^{4}$ Biólogia, Departamento de Entomologia, Fitopatologia e Zoologia Agrícola da Escola Superior de Agricultura Luiz de Queiroz, Universidade de São Paulo, Caixa Postal 9, 13418-900, Piracicaba-SP, salouren@esalq.usp.br.

${ }^{5}$ Eng $^{a}$ Agrônoma, Dra, Chefe do Centro de Qualidade em Horticultura, CEAGESP, Av. Dr. Gastão Vidigal, 1946, 05316-900, São Paulo- SP, adias@ceagesp.gov.br.

${ }^{6}$ Eng $^{\circ}$. Agrônomo, Centro de Qualidade em Horticultura, CEAGESP, Av. Dr. Gastão Vidigal, 1946, 05316-900, São Paulo- SP, hwatanabe@ceagesp.gov.br.
} 


\section{INTRODUÇÃO}

O Estado de São Paulo é responsável por $29,5 \%$ da produção de goiabas do País, com 120.282 t comercializadas em 2004 (www.sidra.ibge.gov.br, acesso em 02 de maio de 2006), das quais $45.620,2 \mathrm{t}$ para mesa e $73.644,8 \mathrm{t}$ para indústria (www.iea.sp.gov.br, acesso em 27 de setembro de 2006). O plantio está distribuído em três grandes regiões que compreendem os municípios de Valinhos, Taquaritinga e Mirandópolis e seus circunvizinhos (Francisco et al., 2005). A produção é típica de pequenos produtores, devido à exigência permanente de tratos culturais, como podas, irrigação e ensacamento dos frutos, no caso da fruta para a mesa. A técnica de envolvimento dos frutos em sacos de papel é usada com o objetivo de reduzir o ataque de insetos (Pereira, 1990). Em outras espécies frutíferas, essa técnica tem por principal objetivo melhorar a qualidade do produto, reduzindo injúrias decorrentes de ataque de pássaros e garantindo melhor aparência aos frutos (Amarante et al., 2002). Não há relatos do efeito do ensacamento na incidência de doenças em goiabas.

Praticamente, a totalidade da goiaba comercializada no Entreposto Terminal de São Paulo (ETSP) da Companhia de Entrepostos e Armazéns Gerais de São Paulo (CEAGESP) é proveniente da produção paulista para consumo in natura ("A goiaba em números" www.ceagesp.gov.br, acesso em 15 de abril de 2006). Em 2000 foi comercializada no ETSP, 23 \% da produção de São Paulo, o que torna esse local um excelente ponto de amostragem de frutos. As goiabas de polpa branca são maioria, embora variedades de polpa vermelha atinjam maior preço médio. O preço médio da goiaba pouco variou na última década (de R\$ 0,60 a $\left.\mathrm{R} \$ 1,50 \mathrm{~kg}^{-1}\right)$. Frutos grandes, de polpa vermelha e de bom aspecto são os mais valorizados.

Injúrias, definidas como sintomas visíveis ou mensuráveis (Chitarra \& Chitarra, 2005), são comumente observadas após a colheita de produtos agrícolas nas diferentes etapas da comercialização. Dentre estas, injúrias mecânicas e doenças póscolheita são as grandes responsáveis pela redução da qualidade dos frutos durante a comercialização. As injúrias mecânicas, além de alterar a aparência dos frutos, estimulam a produção de etileno, acelerando o amadurecimento e, conseqüentemente, reduzindo seu tempo de comercialização (Kluge et al., 2002). As doenças pós-colheita, por alterar os frutos em consistência, cor e sabor, depreciam-nos ainda mais.

As doenças pós-colheita podem ser divididas em duas categorias: (i) as típicas, ocasionadas por patógenos que infectam os frutos após a colheita, freqüentemente através de ferimentos; (ii) as quiescentes, ocasionadas por patógenos que infectam a fruta antes da colheita, mesmo na ausência de ferimentos, permanecendo latentes até a maturação (Barkai-Golan, 2001). Os principais patógenos que causam podridões pós-colheita em goiaba, como Colletotrichum gloeosporioides, C. acutatum, Guignardia psidii e Fusicoccum sp., pertencem à categoria de doenças quiescentes, embora patógenos pós-colheita "típicos", como os dos gêneros Rhizopus e Pestalotia, também ocorram (Barkai-Golan, 2001; Amaral et al., 2006).

Danos são definidos como qualquer redução na qualidade e/ou quantidade produzida (Zadoks, 1985). Não há avaliações precisas dos danos provocados por doenças pós-colheita em frutos tropicais ou subtropicais. As estimativas variam de $10 \% \%$ (Alvarez \& Nishijima, 1987; Durigan, 1999; Benato et al., 2001) a 50 \% (Wilson et al., 1994; Durigan, 1999), em função do produto, da região produtora e da tecnologia empregada na produção. No ETSP, os danos ocasionados por doenças pós-colheita de pêssegos variaram de 2,4 a 15,2 \% dos frutos comercializados nas safras de 2001 e 2002 (Martins et al., 2006). No entanto, essa estimativa foi feita em um único ponto da cadeia produtiva - o mercado atacadista - , sendo razoável inferir que, ao considerar a totalidade da cadeia produtiva, essas porcentagens sejam ainda maiores. Para que medidas de manejo sejam adotadas, evidentemente os danos devem ser bem caracterizados, mas não há nenhuma informação precisa de avaliação de danos póscolheita em goiabas.

O objetivo deste trabalho foi caracterizar e quantificar as injúrias pós-colheita de origens biótica e abiótica em goiabas comercializadas no ETSP e relacioná-las com a prática de ensacamento dos frutos.

\section{MATERIAL E MÉTODOS}

Foram realizadas 13 avaliações entre abril de 2005 e agosto de 2006, em quatro permissionários que comercializam goiabas no ETSP da CEAGESP (Tabela 1). A cada data, foram avaliados todos os frutos de $1 \%$ das caixas comercializadas em cada permissionário. As amostras, que corresponderam às caixas de goiabas, foram estratificadas por cor da polpa, vermelha ou branca; calibre do fruto e local de procedência. Apenas frutos colhidos na véspera e no dia da avaliação foram inspecionados. Quantificaram-se as injúrias mecânicas pós-colheita e as doenças pós-colheita em todos os frutos avaliados. Frutos ensacados foram observados em $65,2 \%$ das caixas amostradas, o que corresponde a $51,1 \%$ dos frutos avaliados.

Todos os frutos com início de sintomas de doenças póscolheita foram transportados ao Setor de Fitopatologia da Escola Superior de Agricultura "Luiz de Queiroz" da Universidade de São Paulo (ESALQ/USP), onde foram incubados sob câmara úmida, durante 24 horas. Após esse período, os frutos foram avaliados diariamente, até uma semana após a coleta. A diagnose foi feita em função dos sintomas e da análise de sinais do patógeno.

A incidência de injúrias mecânicas foi correlacionada à incidência de doenças pós-colheita, por meio de análise de correlação de Pearson. A comparação da incidência de doenças pós-colheita em frutos ensacados e não- ensacados e de frutos de polpa vermelha e de polpa branca foi feita por meio de estatística $Z$ aplicada à tabela de contingência, descrita por Zar (1999).

\section{RESULTADOS}

A incidência de injúrias mecânicas pós-colheita foi muito elevada: $98 \%$ das amostras (caixas) tinham, pelo menos, um fruto injuriado e $63 \%$ dos frutos mostraram algum tipo de injúria. 
A incidência das doenças pós-colheita foi significativamente menor que a de injúrias mecânicas pós-colheita: 34,6 \% das amostras mostraram, pelo menos, um fruto doente e apenas 5,5 $\%$ dos frutos apresentaram sintomas de doenças pós-colheita. A relação entre injúrias mecânicas e doenças pós-colheita foi significativa em frutos ensacados $(R=0,23, p<0,05)$ e nãosignificativa em frutos não-ensacados $(\mathrm{R}=0,09)$. No conjunto total de frutos, apesar de significativa $(R=0,20, p<0,05)$, a relação foi muito dispersa (Figura 1), mostrando ser impossível prever a incidência de doenças conhecendo-se a incidência de injúrias pós-colheita.

A incidência de doenças quiescentes, ou seja, pinta-preta (Guignardia psidii), antracnose (Colletorichum spp.) e podridão de Fusicoccum (Fusicoccum $\mathrm{sp}$.) foi significativamente $(\mathrm{p}<0,05)$ maior nos frutos ensacados $(7,7 \%$ dos frutos) que nos nãoensacados $(2,1 \%$ dos frutos). Por sua vez, a incidência de doenças pós-colheita provocadas por patógenos que penetram os frutos exclusivamente por ferimentos foi significativamente $(\mathrm{p}<0,05)$ maior nos frutos não-ensacados $(0,8 \%)$ que nos ensacados $(0,3 \%)$. A distribuição de freqüência das amostras, por classes de incidência de doenças, mostrou comportamentos bem distintos entre os frutos ensacados e os não-ensacados (Figura 2B). Por outro lado, a distribuição de freqüência das amostras, por classes de incidência de injúrias mecânicas, mostrou comportamento semelhante na ausência ou presença do ensacamento (Figura 2A). Injúrias mecânicas pós-colheita foram observadas em $48 \%$ dos frutos ensacados, diferindo estatisticamente $(\mathrm{p}<0,05)$ dos frutos não-ensacados, nos quais a incidência foi de $43 \%$.

A doença de maior incidência foi pinta-preta (Guignardia psidii), observada em 3,5\% dos frutos. Sintomas de antracnose foram observados em 1,1\% dos frutos. Menos de $1 \%$ dos frutos apresentaram podridões de Fusicoccum, Pestalotia, Rhizopus e Cladosporium.

TABELA 1 - Datas de amostragem, número de frutos e caixas amostradas, e porcentagem de caixas com frutos de polpa branca e caixas com frutos ensacados no pomar.

\begin{tabular}{ccccc}
\hline $\begin{array}{c}\text { Datas de } \\
\text { amostragem }\end{array}$ & $\begin{array}{c}\text { Frutos } \\
\text { (número) }\end{array}$ & $\begin{array}{c}\text { Caixas } \\
\text { (número) }\end{array}$ & $\begin{array}{c}\text { Caixas } \\
\text { com frutos } \\
\text { de polpa } \\
\text { branca }(\%)\end{array}$ & $\begin{array}{c}\text { Caixas } \\
\text { com frutos } \\
\text { ensacados } \\
\text { no pomar } \\
(\%)\end{array}$ \\
\hline $06-04-2005$ & 500 & 32 & 65,6 & 81,2 \\
$12-05-2005$ & 270 & 12 & 41,6 & 58,3 \\
$15-06-2005$ & 805 & 60 & 66,6 & 66,6 \\
$07-07-2005$ & 492 & 36 & 83,3 & 44,4 \\
$09-08-2005$ & 247 & 12 & 41,6 & 41,7 \\
$23-08-2005$ & 489 & 34 & 82,3 & 79,4 \\
$13-09-2005$ & 337 & 20 & 80,0 & 60,0 \\
$18-10-2005$ & 326 & 22 & 59,1 & 54,5 \\
$17-11-2005$ & 277 & 11 & 45,4 & 90,9 \\
$31-01-2006$ & 272 & 13 & 46,1 & 61,5 \\
$23-03-2006$ & 500 & 29 & 79,3 & 58,6 \\
$03-05-2006$ & 380 & 25 & 48,0 & 56,0 \\
$18-08-2006$ & 186 & 17 & 94,1 & 100 \\
\hline
\end{tabular}

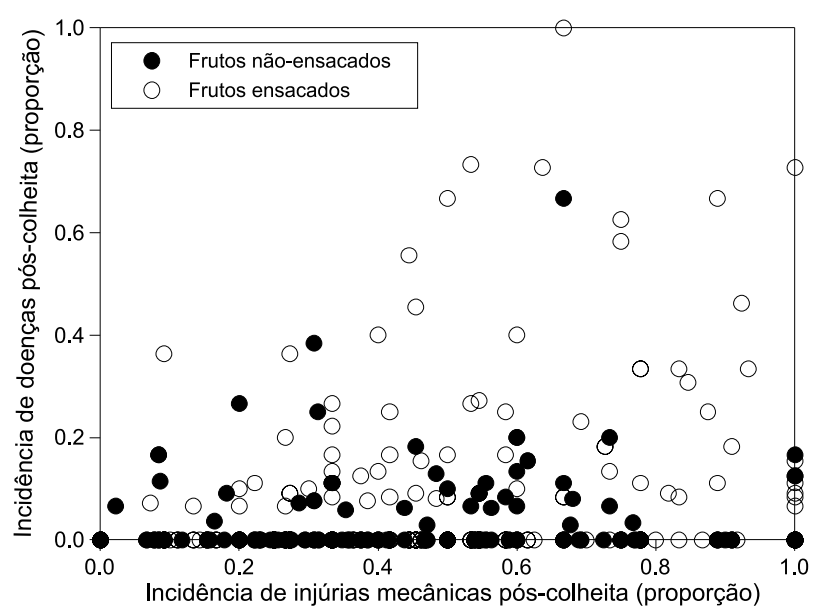

FIGURA 1 - Proporção de frutos com injúrias mecânicas póscolheita e com doenças pós-colheita nas amostras de goiabas avaliadas na CEAGESP, no período de abril de 2005 a agosto de 2006.

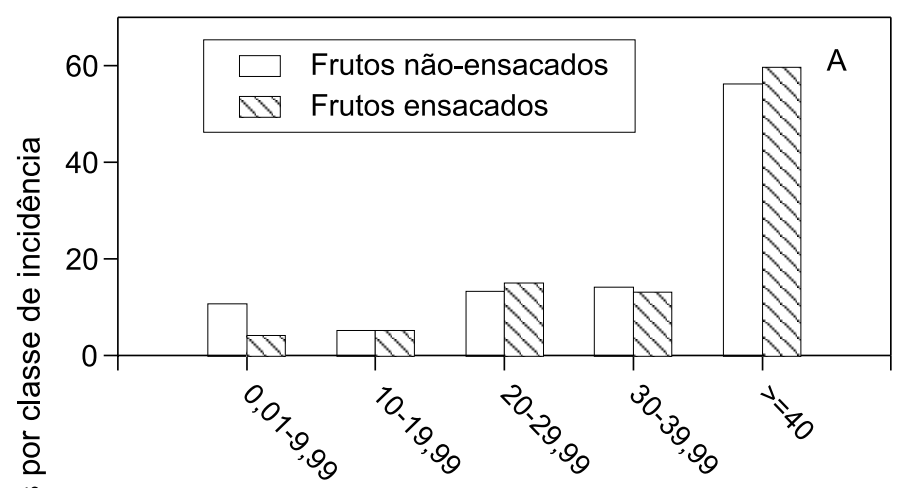

Frutos com injúrias mecânicas por amostra (\%)

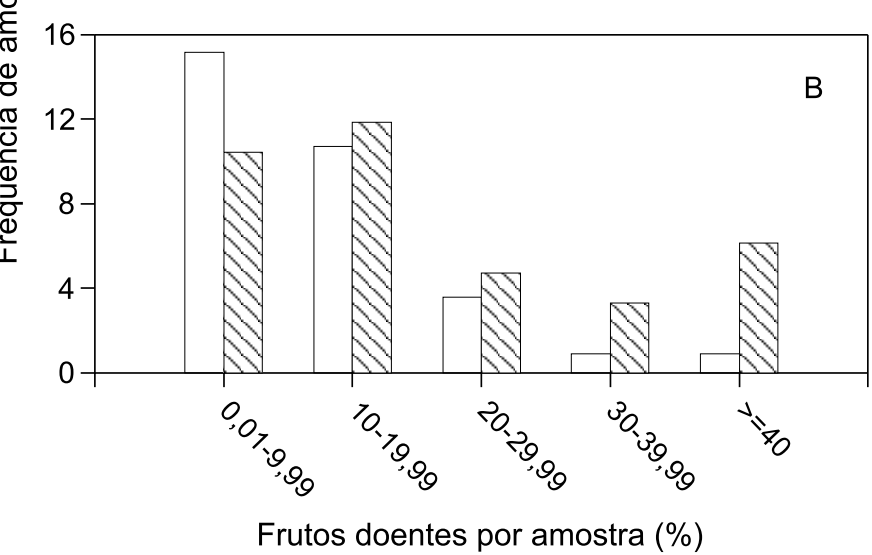

FIGURA 2 - Distribuição de freqüências de amostras (caixas) de goiabas com diferentes incidências de frutos com injúrias mecânicas (A) e com sintomas de doenças pós-colheita (B) provenientes de pomares que ensacam (barras hachuradas) ou não (barras brancas) os frutos. 


\section{DISCUSSÃO}

O ensacamento dos frutos é uma prática comum nos produtores de goiaba de mesa da região de Valinhos-SP. Apesar de eficiente no controle das moscas-das-frutas (Lipp \& Secchi, 2002; Faoro, 2003), seu efeito no controle das podridões fúngicas nunca foi comprovado. De acordo com os dados deste levantamento, o ensacamento é ineficiente no controle de podridões, especialmente daquelas provocadas por patógenos que permanecem quiescentes nos frutos. No caso da goiaba, os três patógenos que causam doenças quiescentes são dispersos por respingos de chuva ou irrigação e o saco de papel não impede a entrada da água que escorre junto ao pedúnculo dos frutos. É provavelmente por essa via que os patógenos chegam aos frutos. Os sacos de papel, tampouco, protegem os frutos das injúrias mecânicas pós-colheita. Embora as incidências de goiabas com injúrias mecânicas em frutos ensacados e não-ensacados tenham sido próximas ( $48 \%$ versus $43 \%$ ), elas diferiram estatisticamente $(\mathrm{p}<0,05)$. Apesar da menor incidência de injúrias mecânicas, frutos não-ensacados apresentaram maior incidência de doenças provocadas por patógenos que penetram via ferimento, como Rhizopus, Pestalotia e Cladosporium, do que os ensacados. Provavelmente, o saco de papel tenha efeito protetor contra o inóculo desses patógenos, dispersos preferencialmente pelo ar e a casca da goiaba ensacada seja mais fina, mais suscetível aos danos mecânicos.

Este levantamento mostrou que, contrariamente ao relatado na literatura (Piccinin et al., 2005), a doença pós-colheita mais freqüente em goiabas de mesa não é a antracnose (Colletotrichum gloeosporioides, C. acutatum), mas a pintapreta, ocasionada por Guignardia psidii. Esses dados corroboram levantamento realizado por Amaral et al. (2006) em dois produtores da região de Campinas- SP, nos quais pinta-preta foi a doença mais freqüente e de maior incidência. Naquele estudo, 18,6 \% dos frutos mostraram sintomas de pinta-preta, com pico de $58 \%$ no mês de abril de 2005. É importante salientar que tanto este relato quanto aquele de Amaral et al. (2006) basearam-se em avaliações de uma única safra (2005-2006), devendo, portanto, ser validados em outras situações (safras/produtores). Elevada incidência de podridão de Guignardia havia sido relatada em 1993 em frutos comercializados em Brasília, provenientes de Brazilândia-GO, e do Estado de São Paulo (Tozetto \& Ribeiro, 1994).

A elevada incidência de podridões no verão de cada ano é uma das causas para que a colheita dos frutos nas propriedades da região de Campinas seja feita antes do ponto de maturação, com conseqüências negativas na qualidade final do produto.

\section{REFERÊNCIAS}

ALVAREZ, A.M.; NISHIJIMA, W.T. Postharvest diseases of papaya. Plant Disease, Saint Paul, v.71, n.8, p.681-686, 1987. AMARAL, C.S.; SALVAIA, A.; ANGELI, S.S.; MARTINS, M.C.; LOURENÇO, S.A.; AMORIM, L. Incidência de patógenos pós-colheita em goiabas Kumagai. Summa Phytopathologica, Botucatu, v.32, suplemento, S57. 2006.
(Resumo).

AMARANTE, C.; BANKS, N.H.; MAX, S. Preharvest bagging improves packout and fruit quality of pears (Pyrus communis). New Zealand Journal of Crop and Horticultural Science, Wellington, v.30, p.93-98, 2002.

BARKAI-GOLAN, R. Postharvest diseases of fruits and vegetables: Development and control. Amsterdam: Elsevier, 2001, 418p.

BENATO, E.A.; CIA, P.; SOUZA, N.L. Manejo de doenças de frutas pós-colheita. Revisão Anual de Patologia de Plantas, Passo Fundo, v.9, p.403-440, 2001.

CHITARRA, M.I.F.; CHITARRA, A.B. Pós-colheita de frutas e hortaliças: fisiologia e manuseio. $2^{\text {a }}$. Ed. Lavras: Editora UFLA, 2005, 785p.

DURIGAN, J.F. Uso da modificação da atmosfera no controle de doenças. Summa Phytopathologica, Jaboticabal, v.25, n.1, p.83-88, 1999.

FAORO, I.D. Técnica e custo para ensacamento de frutos de pêra japonesa. Revista Brasileira de Fruticultura, Jaboticabal, v.25, p. 339-340, 2003.

FRANCISCO, V.L.F.S.; BAPTISTELLA, C.S.L.; AMARO, A.A.A cultura da goiaba em São Paulo. Março de 2005. www.iea.sp.gov.br/out/verTexto.php? codTexto=1902 acessado em 04-09-2006.

KLUGE, R.A.; NACHTIGAL, J.C.; FACHINELLO, J.C.; BILHALVA, A.B. Fisiologia e manejo pós-colheita de frutas de clima temperado. Campinas: Livraria e Editora Rural, 2002. $214 \mathrm{p}$.

LIPP, J.P.; SECCHI, V.A. Ensacamento de frutos: uma antiga prática ecológica para controle da mosca-das-frutas. Agroecologia e Desenvolvimento Rural Sustentável, v.3, p.53-58, 2002.

MARTINS, M.C.; LOURENÇO, S.A.; GUTIERREZ, A.S.D.; JACOMINO, A.P.; AMORIM, L. Quantificação de danos pós-colheita em pêssegos no mercado atacadista de São Paulo. Fitopatologia Brasileira, Lavras, v.31, n.1, p.5-10, 2006.

PEREIRA, F.M. Factors affecting guava production and quality with special reference to São Paulo, Brazil. Acta Horticulturae, v.275, n.2, p.103-109, 1990.

PICCININ, E.; PASCHOLATI, S.F.; DI PIERO, R. M. Doenças da goiabeira. In: KIMATI, H.; AMORIM, L.; REZENDE, J.A.M.; BERGAMIN FILHO, A.; CAMARGO, L.E.A. Manual de fitopatologia: Doenças das plantas cultivadas. $4^{\mathrm{a}}$. Ed. São Paulo: Ceres, 2005, v.2, cap.44, p.401-405.

TOZETTO, L.J.; RIBEIRO, W.R.C. Controle em pós-colheita de podridão em frutos de goiaba (Psidium guajava L.) causada por Guignardia sp. (Phyllosticta psidii) em Brasília. Fitopatologia Brasileira, Brasília, v.19, p.317, 1994. (Resumo).

ZADOKS, J.C. On the conceptual basis of crop loss assessment: the threshold theory. Annual Review of Phytopathology, v.23, p.455-473, 1985.

ZAR, J.H. Biostatistical Analysis. $4^{\text {th }}$ ed. Upper Saddle River: Prentice Hall, 1999, 663p.

WILSON C.L.; ELGHAOUTH, A.; CHALUTZ, E.; DROBY, S.; STEVENS, C.; LU, JY.; KHAN, V.; ARUL, J. Potential of induced resistance to control postharvest diseases of fruits and vegetables. Plant Disease, Saint Paul, v.78, n.9, p.837$844,1994$. 